\title{
TRAINING ECOLOGIST AND BUILDING UP PROFESSIONAL COMPETENCE AMONG ECOLOGY STUDENTS
}

\author{
Alexey Dolgopolov \\ Vasiliy Rud \\ Alexey Cheremisin \\ Vadim Davidov \\ Saint-Petersburg State Polytechnic University, Russia
}

\begin{abstract}
This study attempts to analyze problems which have the process of success forming of high quality professionals-ecologists in university. The adaptation of the students to future life is the widening of horizon of meaning, the development of the professional skills. It is socials and linguistics ability of ecologic and many other too. Teachers must to make skills of students to plan their time, to plan their activity and skills to acquire new information and new methods of economic management. We develop mental abilities for one mark. We need to have the result of economical nature.

Management of activity of members of working group during performance of numerous kinds of research works at field conditions (for example at municipal solid waste (MSW) landfill) or in laboratory conditions puts before the lecturer of environmental disciplines (for example "Waste Management") some difficult pedagogical tasks: to generate stable professional skills of students on application of means of the analysis of an environmental (ecological) situation, on data processing and on development of strategy of effective processing waste. The sphere of the ecological communications includes rules of speech repertoire application, ways of influence on a potential recipient (a student, a partner and an ecologist-curator), adequate speech formulae of submission of commands and formulae of reaction to the acting ecological information. The lecturer should create at students flexible speech skills of possession of Russian language with a view of adequate and duly reaction to the received ecological information, to organize training in field conditions to correct forms of analysis, of forecast and formalization of the data of ecological examination with the help of means of Russian language.
\end{abstract}

\section{KEYWORDS}

Pedagogical aspects, Professional ecologists, Skills, Linguistics ability, Student life, Ecological monitoring, Economic monitoring, Environmental monitoring; Field investigations; Laboratory experiment; MSW Landfill; Bioreactor. 


\section{INTRODUCTION}

Scope of activity ecologist is the programming and the analysis of the compound complex of problems and objectives to running economical process. The ecologic decide many problems. The ecologic have very important function. The assessment of the giving damage and the planning of necessary costs for the restoration and correction ecological situation. The ecologic is the formalization of social activity and the economic is the forms of social practice. Pedagogical aspects of the control of using economic into economical scope are the making and the preparation of personnel which speak professional language and which have professional skills. The professional ecologists need to widen the different methods and opinions for decision of economical problems into ecological areas. The adaptation of the students to future life is the widening of horizon of meaning, the development of the professional skills. It is socials and linguistics ability of ecologic. Ecologists personnel need to prognostication of the new scientific problems and to making the new decisions of real economical problems. It has the base in the active position of the student life. It has the base in the motivation of students. Students mobilize the linguistics and social skills to prognostication in actual situations and in probably situations. For successfully manage the economical process ecologists need to make the pedagogical situations with ecological and economical problems. In scientific conditions and in pedagogical conditions students can acquire needs competences. It is obligatory for pedagogical system of ecological education. The education and the teaching are in domains parallel and it is the flatness of ecological training. Students are making professional skills in process of study to speak ecological terminology. Skills to speak and successfully use the terminology and skills to manage personnel are important content of education. To manage economic process is the art in ecologic area. Successfully management is possible when the people have the global approach mach to make your-self and to make economical skills in ecological scope when the ecologists realize very good the organization of management. Teachers must to make skills of students to plan their time, to plan their activity and skills to acquire new information and new methods of economic management. We develop mental abilities for one mark. We need to have the result of economical nature. Ecologists must set a price in monetary equivalent the ecological operations and actions. Ecologists need to collaborate with business partners. Behaviorism in pedagogic work as the base to progress. Ecological monitoring and economic monitoring at the same time interrelated influence upon communicative skills. It is the base to make economists in ecological domain.

Receiving of skills of carrying out environmental monitoring (at training level) demands efforts of the students studying the forms of research activity (initially in lab-scale conditions). However acquaintance with speech formulae of behavior in speech activity of ecologists-experimenters also is the important pedagogical task. The account of the main functions of application of means of Russian language becomes the necessary tool on creation of manuals on environmental disciplines, instructions under field forms of researches.

\section{RESULTS AND DISCUSSIONS}

Receiving of skills of carrying out environmental monitoring (at training level) demands efforts of the students studying the forms of research activity (initially in lab-scale conditions). However acquaintance with speech formulae of behavior in speech activity of ecologists-experimenters also is the important pedagogical task. The account of the main functions of application of means of Russian language becomes the necessary tool on creation of manuals on environmental disciplines, instructions under field forms of researches. 
Now we should analyze the major functions of Russian language as means of interethnic dialogue for territories of the CIS at servicing sphere of the ecological communications for example on the basis of MSW landfill. Because of creation of a basic word stock on introduction and fastening of using terminological ecological lexicon also is included into a task of lecturer of environmental discipline which cooperates with experts on Russian language. It is necessary to note some the major functions of Russian language as means of interethnic dialogue for territories of the CIS at servicing sphere of the ecological communications.

\section{A) Safety function}

1) Instructing as primary means of non-admission of mistakes. Prevention of mistakes of students-ecologists. Presentation of instructions on operation of environmental equipment;

2) Acquaintance of students with elements of the labware;

3) Recommendations on safety of operation;

4) Feedback (reproductive function) between lecturers and students. Reports of studentsecologists on rules of exploitation of ecological devices, mechanisms, devices;

5) Restriction of activity of students-ecologists with a view of observance of rules of their safety and also for prevention of malfunctions in use of the ecological equipment.

B) Regulatory and communicative function

1) Realization of joint activity of ecologists-partners and other interested persons. Formation of precise and flexible communicative skills during interaction and cooperation between the authorities. Literacy in a choice of adequate speech forms of interaction between members of working group (correction of mistakes, submission of commands, and interaction to them).

C) Service of functions between chiefs and subordinates: at the exploitation of a technical module (bioreactor e.g.). It is expedient to carry out trial educational studies on selfdependent use of given device for effective mastering skills of the general and speech reaction to commands and requests of lecturer and colleagues.

1) Maintenance of communication with the coordinator and partners under the project.

2) Natural forecasting situations (drawing up of models of situations development depending on the received data).

D) Analytical function (making up reports, all kinds of ecological documentation). Language skill to describe an ecological condition of object by means of Russian language becomes an integral part of set of language skills and linguistic, social and professional competence of students.

E) Prognostic function (Problem forming probability scripts of development of global ecocatastrophes); realization of micro forecasts on the basis of the received data and acquaintance of broad masses of the population with probable consequences of ecological catastrophes in mass-media.

F) Functions of duly, adequate and effective reaction to speech behavior of ecologists-experts of coordination services and of speech influence forms of ecologists-experts on potential auditory.

G) Function of service of experimentalist activity: definition of the aim of experiment, a choice of researched parameters, a choice of objects of comparison, finding new methods of data processing, new means of achievement of put purpose. For example, creation of new 
technologies on utilization of waste products in manufacture of different kinds of fuel means of illumination and heating is based on the speech and language units describing an ecological field of activity.

H) The language means serving activity of ecologists, working with a bioreactor (imperative designs of prompting, cause and effect designs of the argument, etc.). We consider attraction and connection of space satellite systems as an innovative method of realization of ecological monitoring with simultaneous application of seismological services, the Emergency Situations Ministry to process of the analysis of a condition of an environment and concrete objects. It is also joint activity of the given services under operative reporting the information on channels of communication to the center by inquiry and analysis of ecological news, messages and maintenance of instant reaction and consultation of ecological groups of monitoring. Global Navigation Satellite System) "GLONASS" at service of ecologists a sent signal of inquiry of the information on a condition of any object of ecological monitoring: it acts from the satellite to controllable object for reception of a necessary reciprocal signal. During creation of new ways of processing of waste products, definitions of an energy potential of ecological objects it is expedient to use language means of scientific style of speech within the framework of the business games simulating work in the field conditions (at MSW landfill e.g.) or laboratory conditions (with a bioreactor e.g.). Interaction from the of Emergency Situations Ministry, seismological services, the organizations on an accomplishment of inhabited files through the Internet as the special form of dialogue of ecologists is obviously necessary in connection with that scales of ecological accidents can be too extensive and as to struggle with disaster most easy together. For example, the working group of ecologists carries out supervision and travels over the certain regions with a view of environmental monitoring at MSW landfills and establishment of laboratory bioreactors in different places located on the remote distance. Simultaneously with the given group, a satellite communication and analysis of the information facilities send a signal of inquiry about environmental condition of object under investigation from the list of the specified items (for example, Ashkhabad, Samarkand, Dushanbe). The data from working groups of experts and satellite devices act to the uniform computer center on verification and processing data. The received information is being operatively traced and analyzed on an authentic basis. Connection of the group to a satellite of communication and to communication facilities of partners forms an opportunity of information interchange of experimental property with a high degree of reliability and speed. The sphere of speech and language repertoir of Russian language in the field of ecology and environmental protection is very rich.

I) when working with ecological services of the states CIS there are discrepancies in ecological and other standards. It needs a base language of dialogue to overcome these discrepancies, to change contents of existing standards, to bring together positions of expertsecologists. This situation Russian language is used. At conclusion of contracts, development and signing of documentation mutual understanding between the partners, expressed in speech cliches and etiquette formulas is necessary. Contractual activity combines in itself elements of two speaking sub styles - scientific style of speech in sphere of jurisprudence and scientific style of speech of area of economic knowledge on the basis of an ecological problematic.

J) Training to draw up competently the texts of ecological examination is obligatory aspect of formation of professional competence. Any ecologist should understand that the destiny of region, ecosystems, a degree and speed of intervention into ecosystems, quality of improvement of an ecological condition depend on his speech and professional competence. 
Being competently made, text of ecological examination causes duly reaction to the occurred malfunctions and accidents, promotes adequate understanding of methods of elimination ecological disasters, problems and mistakes.

K) Formation of bases for computer modeling objects. Modeling of environmental conditions changes, displayed with the help of computer schedules and computer programs is made on the basis of formation lingual and methodical principles of submission of lingual and nonverbal, sign and sub sign material.

L) Creation of universal conditions of bases for adequate passing processes of suggestion to future ecologists of forms of outlook and coexistence with other services on protection and maintenance of ability to live, processes of mastering speech rules and language means of expression of those or others operational components and motivational intensions of ecological practice. For example, at realization of the international cooperation it is necessary to take into account cognitive and ethno cultural features of outlook of partners and to adapt to the given phenomena tolerantly and operatively. During teamwork it is necessary to form speech messages, commands, reply retorts, interrogative, target designs on the basis of operational components (real actions of ecologists, operations under the analysis, gathering, data processing). Motivational intentions represent the requirements caused by ecological practice for realization of the certain actions, and these requirements are expressed by speech means at the moment of realization communicative intentions. Inculcation of skills of uniform application of terms of the ecological content becomes the integral task of lecturer-ecologist.

\section{CONCLUSIONS}

Thus, necessary professional ecological skills on organization of ecological monitoring on the basis of system of Russian language can be formed.

\section{ACKNOWLEDGEMENTS}

The authors are grateful for the support extended by SPbSPU rector Correspondence member of Russian Academy of Sciences Michael Fiodorov, first pro-rector of SPbSPU professor Andrey Rudskoy, first pro-rector of SPbSPU professor Dmitry Arseniev, and also to the head of the Russian language cathedra of the Institute of International Educational Programs of SPbSPU professor Valentina Starodub. 